\title{
ORIGINAL
}

ARTICLES

\section{Faculty Engagement and Productivity During the CoVID-19 Pandemic}

Christine K. Jacobs, MD; Megan Ferriby Ferber, PhD; Max Zubatsky, PhD;

Peter F. Cronholm, MD, MSCE

\begin{abstract}
BACKGROUND AND OBJECTIVES: COVID-19 has had an unprecedented effect on faculty of academic family medicine departments. We sought to characterize faculty's self-reported changes in engagement and productivity in clinical, education, and scholarly efforts during the COVID-19 pandemic, and to correlate the changes with age, gender, and level of COVID-19 exposure. We also sought to determine if differences in faculty engagement and productivity were related to departmental efforts to create virtual community, manage conflict, foster engagement with colleagues, and support faculty emotional well-being.
\end{abstract}

METHODS: We surveyed family medicine department faculty nationally on the effects of the COVID-19 pandemic on their engagement and productivity in clinical care, teaching and research, and on the effect of departmental efforts on well-being.

RESULTS: Most respondents reported decreased engagement and productivity across clinical, teaching, and research domains. Older age and male gender were associated with higher clinical engagement. Most respondents were satisfied with their departments' virtual community but reported that social distancing had a negative impact on departmental ability to problem-solve and on personal emotional well-being. Higher engagement and productivity in all three domains of effort (clinical, teaching, and research) were associated with respondents' well-being and with positive perceptions of their department's efforts.

CONCLUSIONS: Clinical, teaching, and research engagement and productivity for academic family physicians decreased during the COVID-19 pandemic. Faculty well-being and departmental interventions lessened the impact of diminished productivity and research engagement.

(Fam Med. 2022;54(2):107-113.)

doi: 10.22454/FamMed.2022.355977

D andemics such as COVID-19 stress primary care physicians, who must address an evolving catastrophe by transforming practice to meet the needs of patients and communities. ${ }^{1}$ The majority of faculty surveyed at one academic medical center reported significant stress and concerns about their productivity during the COVID-19 pandemic. ${ }^{2}$ Physician stress has often been associated with decreased productivity and

burnout, ${ }^{3}$ resulting in lower empathy and poorer patient outcomes, ${ }^{4}$ thus it is important to understand such associations during the COVID-19 pandemic.

The approach of family medicine departments in response to the pandemic may mitigate the effect of pandemic-related stress on faculty. During the severe acute respiratory syndrome (SARS) outbreak, most health workers reported high stress, including psychological distress, which decreased with perception of support in the workplace. ${ }^{5}$ Effective communication and leadership have been associated with better psychological health of health care professionals. Communication by organizational leaders and a supportive culture can mitigate some of the risk to physician well-being caused by a pandemic, ${ }^{7}$ but it is not clear whether actions taken by academic family medicine departments were effective in the current pandemic.

This study examined how family medicine faculty experienced the COVID-19 pandemic, with respect to their personal levels of engagement and productivity in clinical work, teaching, and research, and whether changes in engagement and productivity were associated with departmental efforts and the faculty's sense of connection and well-being. We examined group differences based on demographics (eg, age and gender) in terms of engagement and productivity to identify groups of physicians who may need greater departmental support.
From the Department of Family and Community Medicine, Saint Louis University School of Medicine, St Louis, MO (Drs Jacobs, Ferber, and Zubatsky); and Department of Family Medicine and Community Health, and Davis Institute of Health Economics, University of Pennsylvania Perelman School of Medicine, Philadelphia, PA. (Dr Cronholm). Center for Public Health Initiatives Leonard 


\section{Methods}

Data were gathered and analyzed as part of the 2020 Council of Academic Family Medicine's (CAFM) Educational Research Alliance (CERA) survey of family medicine educators. CAFM is a joint initiative of four major academic family medicine organizations: Society of Teachers of Family Medicine (STFM), North American Primary Care Research Group (NAPCRG), Association of Departments of Family Medicine (ADFM), and Association of Family Medicine Residency Directors (AFMRD). Pretesting, conducted with family medicine educators who were not included in the sampling frame, evaluated questions for flow, timing, and readability. The American Academy of Family Physicians Institutional Review Board approved this study in November 2020.

Participants were selected based on membership type of one of the CAFM organizations. The pool excluded program directors, clerkship directors, and department chairs, to focus on the faculty experience. The survey contained qualifying questions to ensure surveying only practicing physician educators. Invitations to participate in the study included a personalized greeting and a letter signed by the presidents of each of the four sponsoring organizations with a link to the survey, conducted through the online program, SurveyMonkey. Nonrespondents received four requests, the final request 2 days before closing the survey, to complete the survey.

The survey was distributed to 4,582 candidates. Of these, 177 were returned as undeliverable email addresses and 58 were excluded who had previously opted out of receiving surveys. Additionally, 64 respondents did not meet the qualifying questions and were excluded from further survey questions. The survey was delivered to a final sample of 4,283 family medicine physicians (4,133 in the United States and 215 in Canada) between November 20, 2020, and December 15, 2020.

\section{Survey Questions}

Demographic questions included selfreported age, gender, racial identity and ethnicity, and community size.

We assessed change in effort across clinical, teaching and research domains using two prompts. Participants were asked to indicate what percentage of their time they spent in clinical, teaching and research domains, during September 2019-February 2020 and during March 2020-August 2020. We created change scores by subtracting the percentage indicated in March 2020-August 2020's responses from the September 2019-February 2020 responses. We converted the change scores into a categorical variable with negative scores indicating decreased time, positive scores indicating increased time, and a score of zero indicating no change.

We assessed COVID-19 exposure risk by asking participants to indicate their work-related risk for contracting COVID-19. Participants selected a description of their workrelated risk, with options ranging from no clinical work and working remotely to inpatient care with COVID-19 patients. We coded participant responses into three risk categories based on the level of contact with COVID-19 patients: "low" (no clinical work/fully remote), "moderate" (inperson outpatient or inpatient with no COVID-19 patients service), or "high" (in-person, inpatient service with COVID-19 patients).

We measured engagement and productivity across three domains: clinical work, teaching, and research. Participants were prompted to describe their current levels of engagement and productivity in each of the above roles compared to prepandemic by selecting either "more engaged/ productive" (1), "less engaged/productive" (-1), or "no change" (0). Engagement was defined for participants as "the involvement in, commitment to, or absorption in your work," and productivity was defined as "the accomplishment of the work." Engagement and productivity were treated as separate variables, meaning that a participant could feel more engaged in their work but less productive.

We measured satisfaction with community by asking participants to rate their level of satisfaction with the virtual community created within their departments in response to COVID-19, using a 4-point Likert scale (1="no efforts were made" to 4="exceeded my expectations").

We captured COVID-19's impact using three items. We treated each item as an independent variable (see Table 2 for exact prompts), creating the following variables: social distancing's impact on engagement with department, technology's impact on departmental problem-solving, and department's impact on emotional well-being. We rated the items using a 5-point Likert scale (1="significant negative impact" to $5=$ "significant positive impact").

\section{Analysis}

We conducted analyses were conducted in SPSS (version 27). We analyzed variables using descriptive statistics (eg, frequencies, means, standard deviations) to describe participants' experiences within their departments. We conducted six linear regressions to determine if satisfaction and impact variables, and COVID-19 risk were associated with levels of engagement and productivity (increased, decreased, or no change) in each faculty role. Oneway analysis of variance (ANOVA) tested for significant differences in satisfaction and impact variables based on COVID-19 risk. We also included age and gender in the models. We handled missing data using list-wise deletion.

\section{Results}

The overall response rate for the survey was $20.13 \%(862 / 4,283)$. Within the final sample, response rates for the study questions ranged from $74 \%$ (641/862) to $92 \%(794 / 862)$. See Table 1 for an overview of sample demographics. 
Engagement in Clinical Work, Teaching, and Research

Table 2 shows the rates of change in engagement across clinical, teaching, and research domains. The linear regression models fit the data well (Table 3). Those experiencing better departmental problem-solving, moderate to high COVID-19 risk, and older age reported more engagement in clinical work, while being female was associated with less engagement in clinical work. Higher rates of both satisfaction with one's virtual community and emotional well-being were associated with more engagement in teaching, while older age was associated with less engagement in teaching. Higher emotional well-being was also associated with more engagement in research, while moderate to high COVID-19 risk was associated with less engagement in research. Table 3 shows all associations and their values.

\section{Productivity in Clinical Work,} Teaching, and Research

Table 2 shows the rates of change in productivity across clinical, teaching, and research domains. The linear regression models fit the data well (Table 3). Better emotional well-being was associated with greater clinical productivity. Better departmental problem-solving and emotional well-being was associated with more productivity in teaching. Better emotional well-being was associated with more productivity in research, while high COVID-19 risk was associated with less productivity in research. Table 3 shows all associations and their values.

\section{Departmental Experiences}

The descriptors of participants' satisfaction and impact variables are shown in Table 4. Participants were mostly satisfied with the virtual community in their departments $(\mathrm{M}=2.84)$ but reported that the implementation of social distancing and increased technology use had a somewhat negative impact on their ability to engage with colleagues $(\mathrm{M}=1.98)$, ability to problem-solve in
Table 1: Demographics

\begin{tabular}{|c|c|}
\hline Demographic Variable & $\%$ \\
\hline Age (years) & 48.2 (Mean); 11.4 (SD) \\
\hline \multicolumn{2}{|l|}{ Gender } \\
\hline Female & 61.1 \\
\hline Male & 36.8 \\
\hline \multicolumn{2}{|l|}{ Race } \\
\hline Black/African American & 3.7 \\
\hline Asian & 7.5 \\
\hline White & 83.8 \\
\hline Other & 4.6 \\
\hline \multicolumn{2}{|l|}{ Community Size } \\
\hline$<30 \mathrm{~K}$ & 5.8 \\
\hline $30-75 \mathrm{~K}$ & 11.1 \\
\hline $75-150 \mathrm{~K}$ & 17.2 \\
\hline $150-500 \mathrm{~K}$ & 26.6 \\
\hline $500 \mathrm{~K}-1 \mathrm{M}$ & 14.4 \\
\hline$>1 \mathrm{M}$ & 24.5 \\
\hline \multicolumn{2}{|l|}{ Region } \\
\hline New England & 5.5 \\
\hline Mid Atlantic & 11.5 \\
\hline South Atlantic & 15.4 \\
\hline East South Central & 3.7 \\
\hline East North Central & 19.4 \\
\hline West South Central & 8.5 \\
\hline West North Central & 10.9 \\
\hline Mountain & 10.0 \\
\hline Pacific & 13.3 \\
\hline Canada & 1.9 \\
\hline \multicolumn{2}{|l|}{ CoVID-19 Exposure Risk } \\
\hline Low & 21.8 \\
\hline Medium & 38.4 \\
\hline High & 31.8 \\
\hline
\end{tabular}

$\mathrm{N}=862$

the department $(\mathrm{M}=2.57)$, and their emotional well-being $(\mathrm{M}=1.96)$. An ANOVA was conducted to identify differences in departmental experiences based on COVID-19 risk level. There were no significant differences in the participants' departmental experiences based on their COVID-19 risk level.

\section{Discussion}

During the COVID-19 pandemic, about half of academic family physicians reported decreased productivity in clinical care, teaching, and research. This was significantly greater than small changes in effort, and despite the increased engagement in clinical care and teaching that were reported by about $40 \%$ of faculty. COVID-19 transformed medicine with increased use of virtual medicine,${ }^{8}$ including telehealth primary care visits. ${ }^{9}$ Electronic health record fatigue ${ }^{10}$ and the need for physical distancing ${ }^{11}$ can stress and 
Table 2: Frequencies of Reported Change in Engagement, Productivity, and Time From Prepandemic (September 2019 to February 2020) to Pandemic (March 2020 to August 2020)

\begin{tabular}{|c|c|c|c|}
\hline \multicolumn{4}{|c|}{ Engagement } \\
\hline Domain & Decreased (\%) & No Change (\%) & Increased (\%) \\
\hline Clinical & 27.1 & 30.0 & 42.8 \\
\hline Teaching & 32.2 & 28.1 & 39.7 \\
\hline Research & 44.3 & 30.9 & 24.8 \\
\hline \multicolumn{4}{|c|}{ Productivity } \\
\hline Domain & Decreased (\%) & No Change (\%) & Increased (\%) \\
\hline Clinical & 47.2 & 30.0 & 22.7 \\
\hline Teaching & 51.6 & 28.1 & 20.3 \\
\hline Research & 50.7 & 309 & 18.4 \\
\hline \multicolumn{4}{|c|}{ Time Spent } \\
\hline Domain & Decreased (\%) & No Change (\%) & Increased (\%) \\
\hline Clinical & 20.9 & 54.7 & 24.4 \\
\hline Teaching & 30.0 & 52.6 & 17.4 \\
\hline Research & 30.3 & 60.4 & 9.3 \\
\hline
\end{tabular}

isolate physicians. Increased engagement in clinical work during the pandemic may have been due to the preservation of direct patient care and relationships for some faculty with more intense COVID-19 involvement, while a greater reliance on virtual communication and loss of connection may have disengaged other faculty.

While older faculty were more engaged in their clinical work, female faculty were less engaged clinically during the pandemic. Older physicians in times of stress may be able to draw on their years of patient connections, despite health risks from COVID-19 for older physicians. ${ }^{12}$ The lower engagement of female physicians in clinical work independent of effort correlates with the greater challenges of work-life balance experienced by women ${ }^{13}$ and the distraction and suboptimal focus of telehealth from home ${ }^{14}$ in the setting of greater home responsibilities. Academic family medicine leaders should work to give female faculty additional flexibility and support during crises such as a pandemic, which profoundly affect the home and work environment.

Our finding that half of faculty reported decreased productivity in teaching and research is concerning for the career trajectory of those academic family physicians. Medical school tenure and promotion benchmarks for academic faculty require nonclinical work for advancement. ${ }^{15}$ Accreditation Council for Graduate Medical Education requirements, for example, not only include clinical work and teaching by faculty, but also scholarly productivity such as research, publications, and presentations. ${ }^{16}$ Scholarly output in family medicine, specifically peer-reviewed publications, has shown extraordinary growth over the past decade. ${ }^{17}$ However, a 2016 survey of family medicine chairs revealed that only $34 \%$ of departments reported high levels of department research, whereas $44 \%$ reported minimal capacity. ${ }^{18}$ This vulnerability was highlighted by the pandemic-associated decreased engagement, productivity, and effort in research and teaching relative to the clinical domain. We did not find a gender difference in this, although in a study of science, technology, engineering, mathematics, and medicine (STEMM) faculty, women's self-reported scholarly productivity decreased during the COVID-19 pandemic while men's did not. ${ }^{19}$ Academic departments of family medicine should consider adding faculty development programming or protected time for scholarship, faculty development, or workshops to facilitate collaboration on scholarly projects or publications in the aftermath of the pandemic.

Key aspects of resilience are gratification from clinical practice, connection and self-care practices, and positive attitudes. ${ }^{20}$ In our study, physicians practicing with the highest degree of COVID-19 exposure reported higher levels of engagement. Second, connection with a virtual community and engagement with colleagues were associated with greater engagement and productivity across domains, with the less significant exception of research engagement. Third, emotional well-being and expressed satisfaction with the virtual community created by departments translated to positivity in faculty engagement and productivity. To maximize resiliency in future catastrophic events, departments should seek to support clinical practice and facilitate connection and self-care.

There are some limitations of this study. The survey was conducted at one point in time, 9 months into the pandemic, when faculty may have 
Table 3: Regression Results of the Engagement Variables

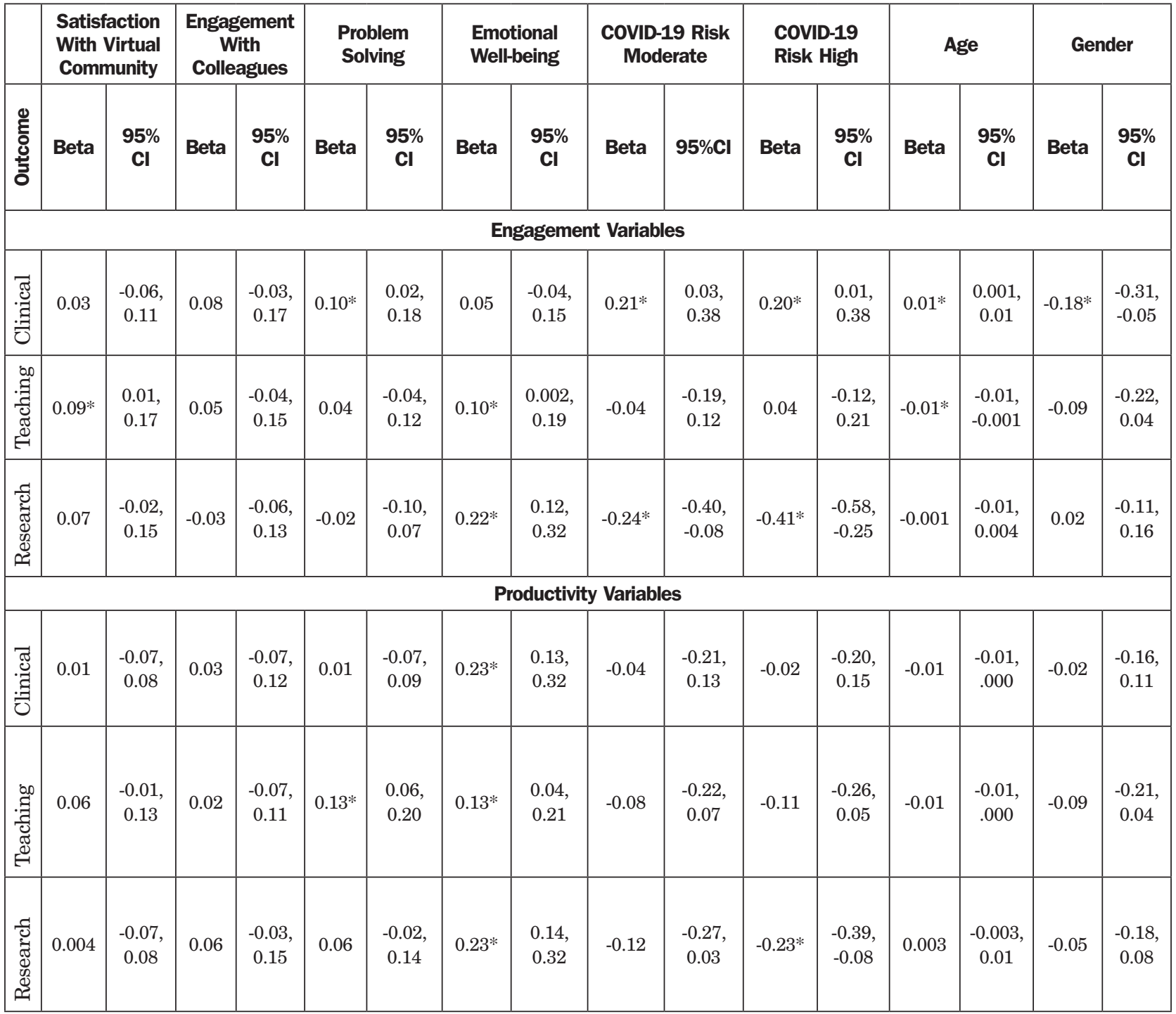

Abbreviation: CI, confidence interval.

* Indicates significance $P \leq .05$. Beta identifies the regression coefficient in the linear regression equation.

Outcome variables (engagement/productivity in clinical, teaching, and research) were coded as 1: "more engaged/productive", -1: "less engaged/ productive", or 0: "no change." The independent variables were the same across the six models and are listed in the first row of the table. The model fit for the engagement in clinical work was $(F(8)=3.83, P<.001)$. The model fit for the engagement in teaching efforts was $(F(8)=2.51, P<.001)$. The model fit for the engagement in research efforts was $(F(8)=7.05, P<.001)$. The model fit for the productivity in clinical efforts was $(F(8)=3.72, P<.001)$. The model fit for the productivity in teaching efforts was $(F(8)=5.96, P<.001)$. The model fit for the productivity in research efforts was $(F(8)=6.79, P<.001)$.

been struggling to find meaningful ways be productive and engaged prior to vaccine availability and prior to loosening of some social distancing orders. This study assessed changes from prepandemic estimates but did not assess the state of departments prior to the pandemic. Due to the time restrictions of collecting data during the pandemic, some of the survey prompts were not validated prior to survey administration. While definitions were given, faculty interpretations of engagement, productivity, and department support may have varied related to different job roles and whether departments had existing telehealth platforms for virtual visits and meetings prior to the pandemic. Finally, although the demographics of the responders mirrored national demographics, the low response rate in this study and varied response rates between regions may limit the generalizability of the effects of COVID-19 on all family medicine departments.

Academic family medicine departments can use the experience of this COVID-19 pandemic to better prepare for future pandemics and catastrophic events, in the midst of the profound changes already occurring 
Table 4: Participants' Experiences in Their Departments

\begin{tabular}{|c|c|c|c|c|c|}
\hline \multirow[b]{2}{*}{ Variable } & \multicolumn{5}{|c|}{ Likert Responses } \\
\hline & $\begin{array}{c}\text { Significant } \\
\text { Negative Impact }\end{array}$ & $\begin{array}{l}\text { Some } \\
\text { Negative } \\
\text { Impact }\end{array}$ & No Impact & $\begin{array}{l}\text { Some } \\
\text { Positive } \\
\text { Impact }\end{array}$ & $\begin{array}{l}\text { Significant } \\
\text { Positive } \\
\text { Impact }\end{array}$ \\
\hline $\begin{array}{l}\text { To what extent have the physical aspects } \\
\text { of social distancing/personal protective } \\
\text { equipment (PPE) impacted your ability } \\
\text { to feel engaged with your departmental } \\
\text { colleagues during the COVID-19 pandemic? }\end{array}$ & $155(19.5 \%)$ & $533(67.1 \%)$ & $75(9.4 \%)$ & $25(3.1 \%)$ & $6(0.8 \%)$ \\
\hline $\begin{array}{l}\text { How has the replacement of in-person } \\
\text { communication by virtual platforms during } \\
\text { the COVID-19 pandemic impacted your } \\
\text { department's ability to effectively solve } \\
\text { problems? }\end{array}$ & $33(4.2 \%)$ & $422(53.1 \%)$ & $202(25.4 \%)$ & $127(16.0 \%)$ & $11(1.4 \%)$ \\
\hline $\begin{array}{l}\text { To what extent has the stress of the } \\
\text { COVID-19 pandemic on your department } \\
\text { affected your emotional well-being? }\end{array}$ & $182(22.9 \%)$ & $490(61.7 \%)$ & $98(12.3 \%)$ & $23(2.9 \%)$ & $1(0.1 \%)$ \\
\hline \multirow[b]{2}{*}{ Variable } & \multicolumn{5}{|c|}{ Satisfaction Responses } \\
\hline & Not at All & Somewhat & Satisfied & $\begin{array}{l}\text { Exceeded } \\
\text { Expectations }\end{array}$ & \\
\hline $\begin{array}{l}\text { What is your level of satisfaction with the } \\
\text { virtual community (eg, virtual huddles, } \\
\text { faculty meetings, one-on-one virtual } \\
\text { meetings) created in your department in } \\
\text { response to the COVID-19 pandemic? }\end{array}$ & $23(2.9 \%)$ & $253(32.0 \%)$ & $341(43.2 \%)$ & $173(21.9 \%)$ & \\
\hline
\end{tabular}

in primary care. ${ }^{21}$ At the time of this study, some sites were not prepared for the COVID-19 pandemic with appropriate procedures or personal protective equipment (PPE). ${ }^{22}$ To recover from this pandemic and prepare for future crises, in addition to material readiness, academic family medicine departments should build resiliency by supporting physician engagement in clinical practice, strengthening virtual communication platforms, and focusing on faculty well-being. Further research should examine whether engagement and productivity recover postpandemic, and the factors associated with that recovery.

CORRESPONDING AUTHOR: Address correspondence to Dr Christine K. Jacobs, MD, Department of Family and Community Medicine, Saint Louis University School of Medicine, 1402 S Grand Blvd, St Louis, MO 63104. 314-977-8480. Fax: 314-977-5268. Christine.jacobs@health.slu.edu.

\section{References}

1. Krist AH, DeVoe JE, Cheng A, Ehrlich T, Jones SM. Redesigning primary care to address the COVID-19 pandemic in the midst of the pandemic. Ann Fam Med. 2020;18(4):349-354. doi:10.1370/afm.2557

2. Huffman EM, Athanasiadis DI, Anton NE, et al. How resilient is your team? Exploring healthcare providers' well-being during the COVID-19 pandemic. Am J Surg. 2021;221(2):277284. doi:10.1016/j.amjsurg.2020.09.005

3. Dewa CS, Loong D, Bonato S, Thanh NX, Jacobs P. How does burnout affect physician productivity? A systematic literature review. BMC Health Serv Res. 2014;14(1):325. doi:10.1186/1472-6963-14-325

4. Bodenheimer T, Sinsky C. From triple to quadruple aim: care of the patient requires care of the provider. Ann Fam Med. 2014;12(6):573576. doi:10.1370/afm.1713

5. Tam CWC, Pang EPF, Lam LCW, Chiu HFK. Severe acute respiratory syndrome (SARS) in Hong Kong in 2003: stress and psychological impact among frontline healthcare workers. Psychol Med. 2004;34(7):1197-1204. doi:10.1017/S0033291704002247

6. Galbraith N, Boyda D, McFeeters D, Hassan T. The mental health of doctors during the COVID-19 pandemic. BJPsych Bull. 2021;45(2):9397. doi:10.1192/bjb.2020.44
7. Dewey C, Hingle S, Goelz E, Linzer M. Supporting clinicians during the COVID-19 pandemic. Ann Intern Med. 2020;172(11):752-753. doi:10.7326/M20-1033

8. Bachireddy C, Chen C, Dar M. Securing the safety net and protecting public health during a pandemic: Medicaid's response to COVID-19: Medicaid's response to COVID-19. JAMA. 2020;323(20):2009-2010. doi:10.1001/ jama.2020.4272

9. Dewar S, Lee PG, Suh TT, Min L. Uptake of virtual visits in A geriatric primary care clinic during the COVID-19 pandemic. J Am Geriatr Soc. 2020;68(7):1392-1394. doi:10.1111/ jgs.16534

10. Khairat S, Coleman C, Ottmar P, Jayachander DI, Bice T, Carson SS. Association of electronic health record use with physician fatigue and efficiency. JAMA Netw Open. 2020;3(6):e207385. doi:10.1001/jamanetworkopen.2020.7385

11. Parmasad V, Keating JA, Carayon P, Safdar N. Physical distancing for care delivery in health care settings: considerations and consequences. Am J Infect Control. 2021;49(8):1085-1088. doi:10.1016/j.ajic.2020.12.014

12. Majeed A, Maile EJ, Bindman AB. The primary care response to COVID-19 in England's National Health Service. J R Soc Med. 2020;113(6):208-210. doi:10.1177/0141076820931452 
13. Ly DP, Jena AB. Sex differences in time spent on household activities and care of children among US physicians, 2003-2016. Mayo Clin Proc. 2018;93(10):1484-1487. doi:10.1016/j. mayocp.2018.02.018

14. Brubaker L. Women physicians and the COVID-19 pandemic. JAMA. 2020;324(9):835-836. doi:10.1001/jama.2020.14797

15. Walling A, Nilsen KM. Tenure appointments for faculty of clinical departments at U.S. medical schools: does specialty designation make a difference? Acad Med. 2018;93(11):1719-1726 doi:10.1097/ACM.0000000000002346

16. Accreditation Council for Graduate Medical Education. Scholarly activity guidelines: review committee for family medicine. Accessed March 4, 2021. https://www.acgme.org/Portals/0/PFAssets/ProgramResources/120_scholarly-activityguidelines.pdf.

17. Liaw W, Petterson S, Jiang V, et al. The scholarly output of faculty in family medicine departments. Fam Med. 2019;51(2):103-111. doi:10.22454/FamMed.2019.536135
18. Weidner A, Peterson LE, Mainous AG III, Datta A, Ewigman B. The current state of research capacity in US family medicine departments. Fam Med. 2019;51(2):112-119. doi:10.22454/ FamMed.2019.180310

19. Krukowski RA, Jagsi R, Cardel MI. Academic productivity differences by gender and child age in science, technology, engineering, mathematics, and medicine faculty during the COVID-19 pandemic. J Womens Health (Larchmt). 2021;30(3):341-347. doi:10.1089/jwh.2020.8710

20. Zwack J, Schweitzer J. If every fifth physician is affected by burnout, what about the other four? Resilience strategies of experienced physicians. Acad Med. 2013;88(3):382-389. doi:10.1097/ACM.0b013e318281696b

21. Verhoeven V, Tsakitzidis G, Philips H, Van Royen P. Impact of the COVID-19 pandemic on the core functions of primary care: will the cure be worse than the disease? A qualitative interview study in Flemish GPs. BMJ Open. 2020;10(6):e039674. doi:10.1136/bmjopen-2020-039674
22. Sasangohar F, Jones SL, Masud FN, Vahidy FS, Kash BA. Provider burnout and fatigue during the COVID-19 pandemic: Lessons learned from a high-volume intensive care unit: Lessons learned from a high-volume intensive care unit. Anesth Analg. 2020;131(1):106-111. doi:10.1213/ANE.0000000000004866 